English Language and Linguistics, 24.1: 75-95. (C) Cambridge University Press 2018. This is

an Open Access article, distributed under the terms of the Creative Commons Attribution-

NonCommercial-NoDerivatives licence (http://creativecommons.org/licenses/by-nc-nd/4.0/), which permits non-commercial re-use, distribution, and reproduction in any medium, provided the original work is unaltered and is properly cited. The written permission of Cambridge University

Press must be obtained for commercial re-use in order to create a derivative work. doi:10.1017/S1360674318000229

\title{
Phrasal compounds can have adjectival heads: evidence from English
}

\author{
CHRISTINE GÜNTHER, SVEN KOTOWSKI and INGO PLAG \\ Heinrich-Heine-Universität Düsseldorf
}

(Received 20 February 2018; revised 4 July 2018)

\begin{abstract}
Phrasal compounds are taken to be word-level structures that combine a lexical head with a phrasal non-head. Several claims have emerged from the pertinent literature: phrasal compounds allegedly only have nominal heads, can host a variety of syntactic structures in non-head position, are determinative, and are instances of expressive morphology. The existence of adjectival phrasal compounds is either explicitly denied in the literature, or considered a marginal phenomenon at best. This article presents data from the Corpus of Contemporary American English (COCA; Davies 2008) that show that adjectival phrasal compounds do exist in English. We demonstrate that they are similar to non-phrasal adjectival compounds and to nominal phrasal compounds. At the same time, they crucially differ from nominal compounds in the prototypical semantic relations between head and non-head: adjectival phrasal compounds are mostly similative-intensifying as opposed to determinative. We argue that this property is also found in noun-adjective compounds and follows naturally from the semantics of the head category in question, viz. adjectives as mostly gradable predicates. In turn, the majority of adjectival phrasal compounds in our data feature a strong expressive component, a characteristic they share with other phrasal compounds.
\end{abstract}

Keywords: adjectival compounds, phrasal compounds, intensification, compound semantics, argumental vs non-argumental compounds

\section{Introduction}

Compounding, the combination of bases, is a highly productive word formation process that is well-researched for quite a range of different languages (see, e.g., Lieber \& Štekauer 2009; ten Hacken 2016). In English, the main focus of interest has been on noun-noun compounds and their properties, such as their semantics, their stress patterns and theoretical issues such as the question of how to distinguish compounds from syntactic phrases (see Bauer et al. 2013: chs. 19, 20 for an overview). More recently, a growing interest has emerged in a more marginal type of compounding, so-called 'phrasal compounds' (e.g. Trips \& Kornfilt 2015b, 2017). Phrasal compounds are complex words that combine a lexical head and a phrasal nonhead, as in example (1) (taken from Trips 2014: 44f., with original punctuation).

(1) (a) a "chicken and egg" situation

(b) the "out of touch" policy

(c) this "Steffi is great" attitude

(d) the "why should it happen to me?" variety 
As shown here, the non-head position can host various phrase types ranging from simpler ones as in $(1 \mathrm{a}, \mathrm{b})$ to full clauses such as (1c) and even interrogatives as shown in $(1 \mathrm{~d})$.

It is generally assumed that phrasal compounds are determinative, i.e. that there is a relation of semantic determination between non-head and head in which the phrasal compound denotes a subtype of the head's denotatum. Furthermore, it is believed that phrasal compounds in English are right-headed and that the phrasal non-head shows a regular phrasal intonation pattern (see, e.g., Trips 2016: 153). The central topics which are addressed in the pertinent literature comprise the inventory of phrasal compounds and their properties within different languages, the problems that the phrasal element pose for morphological theory (such as violations of the Lexical Integrity Principle), and possible solutions to these problems (such as the analysis of the phrasal element as a quote that has word-level status; see Wiese 1996).

Apart from phrasal non-heads, there is another interesting property that seems to set phrasal compounds apart from non-phrasal compounds. While compounds with a lexical non-head can have nominal, adjectival, verbal or prepositional heads, compounds with a phrasal non-head are often claimed to be restricted to nominal heads. Trips \& Kornfilt (2015a: 288), for instance, state that the heads in phrasal compounds 'have to be nominal' and Lieber (1988) considers non-nominal heads as in *[third month of the year] cold $_{\mathrm{A}}$ not licit. Meibauer (2007: 236) mentions that adjectival heads 'are said to be marginally acceptable', while Hein (2011: 343) does not find any adjectival heads in her corpus study and therefore concludes that they have to occur very rarely, if at all. In Icelandic, phrasal compounds with adjectival heads are rarely attested, but seem possible (Bjarnadóttir 2017). Lawrenz (2006: 7-8) mentions seven examples in total for German, for instance:

(2) (a) ein-Ohm-stabil 'one-ohm stable'

(b) berg-und-talverwurzelt 'mountain-and-valley rooted'

Lawrenz also believes adjectival heads to be very rare and further claims that for them, unlike for nominal heads, the non-head must be an NP (see Lawrenz 2006: 135). However, it is very hard to make any claims on the basis of the few attested examples. Thus, it seems that, for German, the status of adjectival heads in phrasal compounds is rather unclear and needs closer scrutiny. For English, the literature does not cite attested examples, but under the assumption that phrasal compounding in English and German does not exhibit crucial differences (see Trips \& Kornfilt 2015a), adjectival phrasal compounds should be (at least) marginally acceptable in English, too.

Drawing on corpus data, we will provide evidence that phrasal compounds in English can indeed have adjectival heads. We will provide an inventory of such compounds and analyze the syntactic and semantic properties of more than 200 adjectival phrasal compounds as gleaned from the Corpus of Contemporary American English (COCA; Davies 2008). We will show that there are differences between nominal phrasal compounds and adjectival ones, and that these differences follow from general properties of adjectives and nouns and are not an effect of phrasal compounding. 
We will first give an introduction to adjectival compounds in English (section 2). This is followed by an explanation of our methodology in section 3. Section 4 provides the structural and semantic analyses of the compounds in our data set. Section 5 summarizes and discusses our findings.

\section{Adjectival compounds: an overview}

Adjectival compounds, i.e. compounds with adjectival heads, have received little attention in the literature. The standard reference works agree that adjectival compounds exist and are productive, but their properties are underresearched. In general, adjectival compounds seem to be quite similar to other kinds of compound, both formally and semantically.

As for the kinds of lexical non-heads they take, all four major classes are attested: nouns, verbs, adjectives and prepositions (see, e.g, Bauer et al. 2013: 452f.). Semantically, adjectival compounds seem to fall into the same major classes as the much better described noun-noun compounds. There are argumental compounds, in which the non-head functions as an argument of the head (sugar-free, flood-prone, kitchen-proud, syllable-final, cost-intensive). Bauer \& Huddleston (2002: 1657) label this category 'incorporated complement/modifier'. The adjectival head may also be a participle, as in palate-exciting, attorney-written, or event-related. Needless to say, this type is only available if the head is argument-taking.

There are also non-argumental compounds, in which the left-hand constituent acts as a modifier. The range of possible interpretations of the relation between modifier and head seems much more restricted than the range found with noun-noun compounds, with the probably most common type expressing a similative relation ('comparative/intensifying' in the terminology of Bauer \& Huddleston 2002: 1657); see (3) for illustration. This meaning is often paraphrased as 'ADJ as NOUN' (for example 'hard as gem' for gem-hard). All our examples are taken from COCA (Davies 2008), unless otherwise specified.

(3) Gem-hard and steel-strong, as the advert says, and, as it doesn't say, jewel-expensive.

Sometimes we find larger families of left constituents, e.g. stone-cold, stone-dead, stone-deaf, stone-hard, stone-gray, stone-blind, stone-broke, stone-heavy, stone-quiet etc. With many such forms, the modifier seems to have taken up a new meaning, expressing intensification. Similar phenomena have been observed for other languages (see, e.g., Booij 2010: 56 for Dutch, or Fleischer \& Barz 1995: 231 for German).

The literature sometimes also mentions another type of modification of adjectives, 'measure terms' (see Bauer \& Huddleston 2002: 1657). (4) illustrates this type.

(4) (a) If I stepped outside the car I would be ankle-deep in thorny vegetation and mud

(b) Each week-long session is $\$ 195$ per camper.

The relative restrictedness of possible relations between the constituents of adjectival compounds may be a consequence of the semantics of the adjectives involved. If 
we include verbal participles in our analysis, many more relations seem to become possible and are attested. (5) gives examples of instrumental, locative, and manner interpretations with the same head, written.

(5) (a) On one of the walls that divided the two stalls where toilets were once installed were chalk-written math problems.

(b) Lewis' partially home-written software - a form of artificial intelligence employing what are known as neural networks.

(c) That manuscript was one of my first attempts a t writing directly in English instead of having someone else translate a French-written text. [typo in the original]

It is not always clear whether a relation would count as modifying or argumental, which may also be the reason why Bauer \& Huddleston (2002: 1657) come up with the category label 'incorporated complement/modifier'. Most of their examples are rather straightforward cases of argumental relations, but some are potentially controversial. Consider (6), which features the adjective blind, which, depending on one's preferred definition of 'argument' vs 'modifier', could be classified as either argument-taking or not.

(6) Bill is religion-blind, color-blind, blind to the differences of people.

With adjectival non-heads we find coordinative interpretations (goofy-crazy, deafmute, true-false decision, dark-light pattern), but also non-heads that seem to function as modifiers, as in light-blue, dark-green, pale-blonde.

The semantic relations exhibited by adjectival compounds seem to correlate with syntactic category to a large extent. Thus similative or argumental relations usually arise (only) with nominal non-heads.

As usual with compounds in English, there are problems in determining what kinds of structure should count as a compound and which ones should be regarded as phrases. Bauer et al. (2013: ch.19) give an up-to-date summary of the criteria and the difficulties involved with their application and interpretation.

Potentially controversial cases are adverbs in left position, which, especially in prenominal position, are often spelled with a hyphen connecting adverb and adjective (for example, ill-advised decision, well-chosen example). However, we do not see compelling arguments why such structures should be considered compounds.

There are no systematic studies available of stress in adjectival compounds. There is variation across and within different types of adjectival compounds, with syntactic position also having a say (see Bauer et al. 2013: 448 for some discussion and examples).

As mentioned in the introduction, very little is known about adjectival compounds with a phrasal non-head. Lieber (1988: 210), Trips \& Kornfilt (2015a) and Trips (2016: 153) take it that they are impossible in English, while Bauer et al. (2013: 456) explicitly say that 'adjectival heads do allow phrases as left sisters'. However, Bauer et al. (2013) do not provide examples to support their claim, nor do they provide an analysis of their properties. The aim of this article is to settle the issue of whether 
adjectival phrasal compounds exist, and to investigate the characteristics of adjectival phrasal compounds in English more closely. In order to find pertinent data we made use of COCA (Davies 2008). Our methodology will be laid out in the next section.

\section{Methodology: corpus analysis}

\subsection{Corpus queries}

Given that adjectival phrasal compounds seem to be a rare species (if one at all), it was necessary to use a very large corpus. We proceeded in two steps consisting of a first pilot study and a second more comprehensive search. The pilot study was part of a bachelor thesis (Schneider 2016) supervised by the first author. The Corpus of Contemporary American English was searched via its web interface. The findings encouraged us to cast our net wider and carry out a second search for the purposes of this article. The second search accessed the 2013 CD version of COCA (Davies 2013) with the help of Coquery (Kunter 2016), a free corpus query tool. We chose COCA as a balanced corpus of American English that is POS-tagged, rather large (c. 480 million words), and contains very recent data.

Phrasal compounds of the nominal type usually come in three different orthographic variants. As indicated in (7), the phrasal non-head can be hyphenated, marked with quotation marks, or both. ${ }^{1}$

(7) (a) the figure-it-out-as-you-go process

(b) the 'Oh , get over yourself' attitudes [typo in the original]

(c) the 'it-can't-happen-to-me' syndrome

For practical reasons, we restricted our searches to hyphenated phrasal non-heads. In her study on nominal phrasal compounds in the British National Corpus, Trips (2016: 155f.) finds that hyphenated phrasal compounds "predominantly display "symmetric" patterns such as N-and-N, N-to-N or N-by-N' and often contain lexicalized phrasal expressions, while those with quotation marks 'frequently include a predicate and exhibit phrases that are full sentences built on the fly'. Thus, the preferred spelling strategy seems to correlate with certain types of phrasal non-heads, and restricting oneself to hyphenated expressions may seem too narrow. However, the main aim of this article is to investigate whether the allegedly non-existent structure does exist, rather than to provide an exhaustive list. As will be demonstrated in section 4, we do find different types of phrasal non-heads in our data, covering all the phrasal categories listed in Trips (2016). The use of a subset of the potentially available data is thus unproblematic.

The first corpus query targeted strings of words that contain three or more hyphens, followed by an adjective and a non-nominal element, as shown in (8).

\footnotetext{
${ }^{1}$ Trips (2016) points out a fourth option: orthographically unmarked phrasal non-heads. These, however, are not easily searchable via a string search in a corpus.
} 
(8) $*_{-} *_{-} *_{-} *[j *]-[n n *]$

By adding '-[nn*]' to the query string, constructions with nouns in post-adjectival position were excluded, since the scope of the modification relation is often not clear in such cases. In (9a) and (9b), for example, the hyphenated phrases could be modifying the respective adjectives, but more likely (also) scope over the nouns.

(9) (a) the after-the-lights-go-down magical experience

(b) not-ready-for-prime-time dirty word

Consequently, our data comprise only adjectival phrasal compounds in predicative position. $^{2}$

In the second query, we searched for strings that contain two or more hyphens followed by an adjective and a non-nominal element. Both data sets were merged and subjected to extensive manual checking in order to weed out hyphenated strings which were clearly not candidates for the status as adjectival phrasal compounds, because they either were not compounds, not adjectival, or did not have a phrase as non-head. Attestations that were ambiguous as to these criteria were also removed in this step. Such cases included, for example, non-words (e.g. v-e-r-r-r-y, m-m-most or phone numbers), cases of items wrongly tagged as adjective or non-noun (A how-to-do-it manual for librarians or today's not-always-pretty national populist), and items where the hyphenated string does not modify the adjective following, as in (10).

(10) I'm going to shoot that son-of-a-gun dead as a doornail.

Adjectives used as nouns, as in the following example, were removed, too. In such cases it is unclear whether the construction involves an empty nominal head (see Günther 2018). If so, the compound would be atttributive and therefore outside the scope of our search. If one assumed that the whole expression is nominal, we are not dealing with an adjectival compound in the first place.

(11) what cultural critic and writer Nelson George calls the 'I'm-in-total-control cool.'

We also excluded sentences in which the scope of the modificational relation was ambiguous. For instance, in (12) it is not certain whether word-for-word unambiguously scopes over wrong.

(12) And it's word-for-word wrong in such a way that it angers me

The remaining data were coded for various properties. This coding procedure sometimes involved further specification of certain criteria, which occasionally led to the exclusion of particular items. This will be explained in the next subsection.

\footnotetext{
2 This does not mean that attributive adjectival phrasal compounds do not exist. In fact, we came across some unambiguous ones, for example his red-wool-and-silk miniskirted girlfriend or ranging from sour-cream-andclam flavored chips in Maine to shish-kebab flavored ones in Egypt. For the reasons outlined, we do not attempt a systematic investigation of attributive adjectival phrasal compounds in this article.
} 


\subsection{Coding decisions and exclusion of items}

We coded the data for phrase type of the non-head as well as for the relation between non-head and head. We distinguished the following phrases: noun phrases, adjective phrases, adverb phrases, prepositional phrases, verb phrases, full clauses and nonphrases. Some of these categories need further explanation. First, we did not keep apart noun phrases and determiner phrases. There are instances of both types of structure in our data set, and there are cases among them that do not allow for making this distinction since they feature bare nouns (plural forms or mass nouns) as heads of the premodifying phrase. The distinction between verb phrases and full imperative clauses poses similar problems. We opted for a very narrow classification: only those items were treated as imperatives, and hence as full clauses (CPs), which included the marker please. All other verb-object or verb-modifier structures were classifies as VPs.

Another potentially controversial case is the distinction between adverbs and prepositions. Here, we followed Pullum \& Huddleston's (2002: 598-603, 612-17) wider definition of adpositions. Unlike the more traditional approach to adverbs, they recognize intransitive uses of prepositions in English (see Emonds 1972; Jackendoff 1973). Based on this idea, we classified both intransitive items such as out-and-out and transitive items such as out-of-mind as prepositional phrases. This leaves nonheads such as the following as true adverb phrases:

(13) (a) oh-so-very-much worse

(b) all-too-readily available

Items with an adverb phrase as phrasal non-head were omitted from the final data set. Since the syntax readily allows for modification of adjectival heads by adverb phrases, it is unclear how to set apart phrasal compounding from syntactic modification in these cases. (Note that this might be the reason why adjective phrases as phrasal non-heads are hardly discussed in the literature on nominal phrasal compounds in English.)

The final category that needs further explanation is 'non-phrasal'. Needless to say, the non-head in a phrasal compound is a phrase. The decision on what counts as phrase, however, is not always straightforward. The line between compounding and syntax is generally known to be difficult to draw, and this problem also holds for triconsituent compounds (see again Bauer et al. 2013: ch.19). We followed a rather conservative strategy and excluded all items consisting of a concatenation of words of the same syntactic category, as these lend themselves easily to an analysis as compounds. Such items are illustrated in (14).

(14) (a) air-traffic-control related

(b) shaving-cream-commercial handsome

There are also cases where the premodifying construction is headed by a nominal compound that is modified by an adjective, as shown in (15). We included such instances, irrespective of potential lexicalization of the non-head construction. This decision affects seven items. 
(15) (a) Chinese-water-torture crazy

(b) brown-paper-bag boring

(c) hot-caramel-fudge-sundae endearing

The general problem that arises in this context is how to treat lexicalized expressions. We decided to follow the literature on phrasal compounds, which acknowledges lexicalized expressions as phrasal non-heads (see, e.g., Meibauer 2003; Trips 2016), and thus included lexicalized phrasal non-heads (such as, for example, in-your-face).

As laid out in section 2, there are three possible relations between the non-head and the head in adjectival compounds: argumental (as in event-related), non-argumental (i.e. modificational as, for example, in steel-strong), and measure-defining (as in ankle-deep). The same three-way classification was applied to the phrasal adjectival compound data, as illustrated in (16), with an example of each category.

(16) Non-argumental It was absolutely knock-down knock-your-socks-off spectacular.

(17) Argumental and the collar is chin-and-nose friendly with a soft fleece lining.

(18) Measure That is a three-mile wide difference with the current administration.

The items with measure relations were excluded from the data for several reasons. First, the phrasal status of the modifiers is often unclear because they sometimes are inflectionally defective (see also Bauer \& Huddleston 2002: 1660). Second, the very existence of these structures is uncontroversial, so showing that they are attested in a corpus is a moot point. Third, similar structures with nominal heads (for instance three-syllable word, four-wheel drive, three-year period have not been analyzed as phrasal compounds in the literature (e.g. Bauer et al. 2013: 437). We will therefore restrict our searches to the clear cases of phrasal compounds, excluding measure phrases.

\section{Results}

The corpus queries and the data-cleansing procedure rendered 207 instances of phrasal adjectival compounds. The subsequent section describes their structural properties, section 4.2 provides a semantic analysis.

\subsection{Structural analysis}

The 207 phrasal compounds comprise 187 instances of canonical adjectival heads, 14 instances of $e d$-participles in head position, and 6 instances of ing-participles. The number of constituents in the phrasal non-head ranges from three as in (19a) to ten as in (19b).

(19) (a) at least in part, you always felt so crazy-as-catshit scared.

(b) if you don't mind my boldness, you look stunning. Make-'em-run-round-aroundthe-block-howling-in-agony stunning. 
The formal properties of the non-heads by-and-large match those of the non-heads in nominal phrasal compounds listed in Trips (2016). Each of these phrasal categories is described in what follows.

Noun phrases. There is a range of different types of noun phrases in the data. They may or may not contain a determiner, can have prenominal or postnominal dependents, and can be coordinated.

(20) (a) one-skier-at-a-time narrow

(b) edge-of-your-seat scary

(c) brown-paper-bag boring

(d) cost-and-cash intensive

Prepositional phrases. The prepositional non-heads in our data display full or defective NP complements, as well as coordination.

(21) (a) up-to-the-minute modern

(b) out-of-mind insecure

(c) out-and-out crazy

Verb phrases. There are different types of verbal structures. They can be finite or non-finite, the verbs can take dependents of various kinds, and there are again instances of coordinated verbs.

(22) (a) hides-the-dirt brown

(b) eat-off-the-floor clean

(c) salting-raw-sores hot

(d) melt-in-your-mouth sweet

(e) make-your-stomach-hurt difficult

(f) kill-or-cure desperate

Full clauses. The full clauses in our data comprise imperative, declarative and interrogative structures.

(23) (a) please-do-that-again amazing

(b) it-came-from-outer-space odd

(c) is-she-really-human beautiful

The data do not comprise 'directives with let' and 'full sentences including interjections' (see Trips 2016), which is likely an effect of a smaller database rather than a structural constraint.

Adjective phrases. In addition to the non-head structures listed in Trips, there are several instances of adjective phrases in non-head position. The adjectives show posthead dependents or coordination.

(24) (a) weak-in-the-knees tired

(b) black-and-white strict 
As mentioned in the previous section, the data set contains lexicalized and nonlexicalized expressions. Not too surprisingly, especially among the short three-word non-heads, there are lexicalized expressions (laugh-out-loud funny, in-your-face aggressive, off-the-charts gorgeous), while the longer ones are usually non-lexicalized, transparent formations (poke-me-in-the-eye dull).

To summarize, we find the same range of modifying phrases for adjectival phrasal compounds as for nominal phrasal compounds. Claims that adjectival phrasal compounds can only have NPs as non-heads (e.g. Lawrenz 2006 for German) are wrong.

\subsection{Semantic relations and the contribution of (non-)heads}

This section describes semantic characteristics of the data set described in section 3, primarily classifying the relations between non-head and head along the lines illustrated in section 2 .

Just as for adjectival compounds in general, we find both argumental and nonargumental phrasal compounds with adjectival heads. Non-argumental ones are, however, far more frequent than argumental ones. ${ }^{3}$

In order to set these two classes apart, we follow the discussion in Bauer et al. (2013: ch. 20). Thus, only cases in which the non-head can serve as a core argument of the head, typically as what would be the subject, prepositional object, or phrasal complement in syntactic paraphrases, are included in the set of argumental compounds. This applies to eleven items in our data. As in (25), more than half of these include past-participle adjectives in head position where the compound semantics follows the base verb's argument structure:

(25) (a) Over the last half of the 1990s, we were all a little bit too shareholder focused, too growth-at-any-cost focused

(b) The pop star refused to acknowledge anything mistletoe-and-holly related until after her big day.

We also find argumental compounds with other kinds of argument-taking adjectives, as illustrated in (26).

(26) (a) text-centered (structuralism, poststructuralism, and deconstruction) or text-andreader interactive (reader-response criticism and reception theory).

(b) the storable hood is detachable, and the collar is chin-and-nose friendly with a soft fleece lining.

(c) It's been a challenge to get the meters plug-and-play ready.

All eleven argumental compounds are determinative, as the non-heads semantically determine the respective heads and the compound denotations form subclasses of the head denotations. In the following, we will call this relation 'classifying'.

${ }^{3}$ This may in fact be the consequence of our search string. It may be that many argumental adjectival phrasal compounds are spelled with a hyphen even before the head adjective, as in red-and-white-striped. The quantitative distribution of argumental vs non-argumental phrasal compounds is left for future research. 
However, non-argumental compounds form the by far larger group in our data with 196 cases in total. In (27), for instance, the respective heads are neither derived from verbs or nouns, nor are the non-heads possible arguments of the head adjective:

(27) (a) They come from the Home Made Bakery in Wailuku which will sell them only straight-out-of-the-oven hot: [...]

(b) But I was out-of-mind insecure about hiring such a young man.

Such data allow for the general semantic observation that the vast majority of nonargumental compounds display an intensifying semantics. The non-heads generally serve a boosting function and are rarely compromising, diminishing, or downtoning. ${ }^{4}$ This is illustrated by further examples in (28):

(28) (a) The short ribs [...] tasted like a classic Midwestern pot roast and were falling-offthe-bone tender.

(b) A hotel bedroom and bathroom should be eat-off-the-floor clean. And no smells.

(c) it sports a blade of racy M4 steel, a fine-grained powdered steel that's out-of-thisgalaxy sharp.

(d) $[\ldots]$ is ED WOOD, 30, our hero. Larger-than-life charismatic, confident, Errol Flynn-style handsome

The general interpretation of (28a) is certainly 'tender to a very high degree', in (28b) we find 'clean to a very high degree', and so on. Thus, these typical examples follow the non-argumental modifier-head pattern with an intensifying semantics exemplified for adjectival compounds in general in section 2 above. The examples in $(28 \mathrm{a}, \mathrm{b})$ also show that intensification is often accompanied by a vague similative interpretation. In the majority of cases this similitude is established in reference to some hyperbolic situation (e.g. falling off the bone, eating off the floor). In other examples, such as $(28 \mathrm{c}, \mathrm{d})$, similitude does not play a decisive role.

Perhaps unsurprisingly, our data do not feature any coordinate compounds. These seem to be ruled out on structural grounds by the categorial sameness condition on head and non-head. Fulfilling this condition for phrasal compounds would, by definition, entail a phrasal head constituent; see Bauer et al. (2013: 489f) and Meibauer (2003: 155) for analogous reasonings concerning the non-existence of nominal phrasal coordinate compounds. Even if one assumed that a structure like [AP]-A could in principle be interpreted as coordinative, such cases are still not found. In (29), for example, the contribution of the non-head AP is again intensifying. The data are, without exception, right-headed both structurally and semantically.

(29) $[\ldots]$ is perhaps best summed up by his Tequila: It'll get you flat-on-your-face drunk which is what it's all about

\footnotetext{
${ }^{4}$ Unless indicated otherwise, we will use intensification and degree modification interchangeably to include all forms of degree expressions, irrespective of whether they are boosters, downtoners, diminishers, or compromisers. See, for example, Bolinger (1972: 17-18) for more detailed discussion of these categories.
} 
We also find a few non-argumental compounds with classifying rather than intensifying interpretations, as shown in (30):

(30) (a) And she was classy. As in year-in-England classy, with a sort of mid-Atlantic accent that made you think maybe she was Canadian.

(b) Say something funny. Not lawyer-and-a-lightbulb funny but something that takes into account the tenseness of the situation.

Here, the likely interpretations appear to be 'classy as someone who spent time in England' and 'funny as the humor in a particular kind of joke' rather than 'classy/ funny to a high degree'. Thus, the relation is primarily similative (see section 2). In turn, there are items for which the line between classification and intensification appears (even) more blurred as in (31).

(31) (a) But his eyes were bright blue, center-of-a-flame blue, simultaneously cool and hot.

(b) Hunter Fans come in more than 150 styles and colors ranging from turn-of-thecentury traditional to state-of-the-art contemporary.

(c) George Washington slept here. Though the decor is up-to-date comfy, one early tradition holds fast: [...]

In (31a), we do find the classifying reading of a particular shade of color typical of some adjectival compounds with color adjectives as heads (see Bauer \& Huddleston 2002: 1656). Yet the example additionally suggests degree-modification. Similarly, the likely interpretation of turn-of-the-century traditional in (31b) is both classifying (i.e., 'in relation to/pertaining to traditions from the turn of the century') and intensifying (i.e. 'very traditional'). ${ }^{5}$ If we code examples such as these 'mixed' (i.e., as both classifying and intensifying), the overall distribution of the data looks as given in table 1 .

The predominant intensifying pattern found with adjectival phrasal compounds is very similar to what we often find with noun-adjective compounds, exemplified in (32) (see section 2); examples taken from the OED (2017), Bauer \& Huddleston (2002), Marchand (1969):

(32) ice-cold; bone-dry; crystal-clear; dog-tired; dog-poor; stone-deaf; stone-cold; stock-dead; stock-blind etc.

This pattern oftentimes displays semantic bleaching of the comparison-contributing non-head, which then loses 'its intellectual motivation, thus coming to serve as a mere intensifier' (Marchand 1969: 84). Hoeksema (2012), working with Dutch data mostly, and Bauer (2017: 100f.) call them 'elative' compounds and understand their high degree reading as crucial. The intensifying phrasal compounds with adjectival heads in

\footnotetext{
5 Alternatively, we could argue that the item is ambiguous and the respective reading down to the question of how the head is classified. Similar classification problems appear with other items in which the non-head contributes some form of time- or era-related modifier and the head is not clear-cut gradable: for example, in state-of-the-art real or turn-of-the-millennium contemporary.
} 
Table 1. Distribution of (non-)argumental compounds with classifying, intensifying, or mixed interpretations; $N=207$, percentages are rounded

\begin{tabular}{lcccc}
\hline \hline & Non-argumental & Argumental & Total & Percentage \\
\hline Classifying & 11 & 11 & 22 & 11 \\
Intensifying & 161 & 0 & 161 & 78 \\
Mixed & 24 & 0 & 24 & 12 \\
Total & 196 & 11 & 207 & 100 \\
Percentage & 95 & 5 & & 100 \\
\hline \hline
\end{tabular}

our data share several characteristics with elative compounds: they are not superlatives (This beer is ice-cold, but that one is even colder; see (33a)), they appear odd with very-modification and comparative morphology (??a very ice-cold beer, see (33b); ??This beer is more ice-cold than that one, see (33-c)), and they seem to elude nominalization (??the ice-cold $d_{\mathrm{N}}$, see (33d)).

(33) (a) This chilli is rip-your-lips-off hot, but my mom's is even hotter.

(b) ??This chilli is very rip-your-lips-off hot.

(c) ??This chilli is more rip-your-lips-off hot than that one.

(d) ??The rip-your-lips-off heat

Wrapping up the findings thus far, there are both argumental and non-argumental phrasal compounds with adjectival heads. The majority of the compounds in our data set are non-argumental intensifying compounds and behave similarly to elative compounds described in the literature, with a fuzzy line between intensifying and similative relations. Non-argumental compounds with classifying interpretations are only found occasionally, while all argumental compounds are classifying. All examples are right-headed and no coordinate compounds feature in the data.

Contrary to assumptions in the literature (see Meibauer 2003; Trips 2016), phrasal compounds can have adjectival heads, and with these compounds other semantic relations than determination, classification, or subkind-establishment are possible. These two findings are closely connected and have their origin in the nature of the head category itself, i.e. the adjective. Let us look in more detail at the adjectival heads.

It is largely accepted in the literature that degree modification presupposes gradability of what is modified, in our case, the adjective in head position. Most adjectives are prime examples of gradable expressions that introduce scalar structure (see, among many others, Bierwisch 1989; Kennedy \& McNally 2005; Rotstein \& Winter 2004; see Rainer 2015 for intensification in word-formation). Therefore, for our data we expect the dominant semantic relation, i.e., intensifying modification, to go together with gradable heads. To test this, we applied an extension of the tripartite adjective 
typology of Kennedy \& McNally (2005) and Kennedy (2007) to our data. ${ }^{6}$ The majority of heads in non-argumental compounds are clearly gradable according to the typology used (93 percent), with roughly two-thirds being relative adjectives (67 percent).

Among the few presumably non-gradable heads, we find, for example, four ethnic adjectives (Irish; Chinese; American; middle American), i.e., items that are oftentimes considered relational adjectives (we also find traditional $(2 \mathrm{x})$ and organic (in the sense of 'relating to organs') as other typically relational exemplars). Yet it is unclear whether any of these should be considered relational at all in their respective contexts in our data. First, relational adjectives have the well-known tendency to occur in attributive use only (see Levi 1978; see McNally \& Boleda 2004 for possible exceptions), a syntactic pattern our corpus search excluded for methodological reasons (see section 3). Incidentally, this arguably explains parts of the distribution of the data: extending the corpus search to more syntactic environments may well lead to an increase in the number of phrasal adjectival compounds with classifying interpretations and/or relational heads. Second, it is not uncommon for relational adjectives to form quality polysemes (see Levi 1978) and arguably any adjective, or one of its polysemes, can be coerced into a gradable reading upon sufficient contextual support (see Bauer et al. 2013: 104f.). Even longer contexts, as in (34), do not unambiguously allow decisions on whether we are possibly faced with quality polysemes rather than true relational adjectives.

(34) To this day, I'm not exactly sure what he said that was so persuasive - the husky Irish accent, maybe, not full-blown faith-and-begorra Irish but with enough of a lilt to make my mouth want to smile. (2008 FIC)

Irrespective of these caveats, we have established that the majority of heads in our data are (relative) gradable adjectives, which is unsurprising given the data's predominant intensifying semantics. At the same time, this distribution begs the question of whether there are adjectival heads that are better suited for featuring in phrasal compounds. Following more fine-grained, notional adjective classifications (see, e.g., Bache \& Davidsen-Nielsen 1997; Dixon 1982), we find a rather eclectic range of attested heads. Possible adjectives (attested in our data set) are, for example, dimension (narrow; cheap), evaluative (difficult; fabulous), human propensity (stubborn; crazy), or physical state adjectives (drunk; fresh). However, the clearly most frequent notional classes are evaluative and human propensity adjectives, i.e. (mostly) relative adjectives typically used for subjective value judgements of entities (on the subjectivity of concepts encoded by adjectives, see Frawley 1992; Kennedy 2013; Solt

\footnotetext{
${ }^{6}$ Adjectives were assigned to four different classes: relative and absolute gradable adjectives, extreme adjectives, and ungradable adjectives. Test environments included compatibility with comparative morphology and very-modification, with fully- or slightly-modification, and with extreme degree-modifiers such as downright or flat-out; see Kennedy (2007), Kennedy \& McNally (2005), Morzycki (2012; 2016: 140-4) for details.
} 
2016). Upon combining these two subclasses, the pattern $\left[\mathrm{XP}-\mathrm{A}_{\text {evaluative/human propensity }}\right.$ $=$ intensifying semantics] accounts for 123 out of a total of 207 items, i.e. 59 percent. ${ }^{7}$

This preponderance of evaluative and human propensity adjectives concurs with another characteristic of the phrasal compounds in our data set: most non-argumental compounds display some form of expressivity (see Bauer 1997, Haspelmath 1999, Zwicky \& Pullum 1987 for the notion of expressivity in morphology). ${ }^{8}$ Zwicky \& Pullum (1987: 335), for example, define expressive morphology as 'associated with an expressive, playful, poetic or simply ostentatious effect of some kind', while Meibauer (2007: 246) understands expressivity as 'a language property that has to do with emotions or emotion-related evaluations'. Thus, in the realm of adjectives, it seems unsurprising that we find forms of expressive morphology in particular with adjectives that themselves denote evaluations or psychological characteristics attributed to humans. Typical examples of this kind are illustrated in (35):

(35) (a) $[\ldots]$ is ED WOOD, 30, our hero. Larger-than-life charismatic, confident, Errol Flynn-style handsome

(b) Tina had been born beautiful. Stop-traffic, is-she-really-human beautiful.

This is in accordance with accounts of nominal phrasal compounds (see Meibauer 2007, 2015; Trips 2012, 2014). Meibauer (2007), for example, takes expressivity or wittiness as the pragmatic raison d'être of phrasal compounds, which he claims to be in competition with non-phrasal complex words or syntactic structures. Trips (2012), among other things, conducts a quantitative register-based analysis of data from the British National Corpus and establishes an explicit connection between expressivity or wittiness and text genre. Disregarding possible explanations for the distribution, she finds that nominal phrasal compounds are a phenomenon of written language and predominantly found in magazine and periodical writing. Using the coarse registerclassification straightforwardly available in COCA, the data distribution illustrated in table 2 is fairly similar to the one found by Trips for nominal phrasal compounds. While also a written phenomenon first and foremost, the numbers for spoken, academic, and fictional registers are slightly higher.

Finally, several non-heads in our data contribute more than mere intensification or expressivity. In particular many relative adjectives are both inherently vague and

Table 2. Distribution of adjectival phrasal compounds over COCA's 5 main registers; $N=207$, percentages are rounded

\begin{tabular}{lccccr}
\hline \hline & Academic & Fiction & Magazine & News & Spoken \\
\hline Frequency & 11 & 62 & 74 & 49 & 11 \\
Percentage & 5 & 30 & 36 & 24 & 5 \\
\hline \hline
\end{tabular}

\footnotetext{
7 This measure includes the mixed class ('intensifying + classifying').

${ }^{8}$ With the exception of a few non-heads consisting of functional material only, such as out-and-out spectacular.
} 
exhibit polysemy (see, among many others, Kennedy 2007). What is at stake here, is the classic question of how the necessary comparison classes for vague adjectives are being retrieved contextually (see, for example, the discussion in Partee 1995). As shown in (36), run-of-the-mill intensification with adverbs typically does not contribute to the resolution of vagueness or polysemy and, say, hot can be degreemodified in this vein irrespective of the noun it predicates over:

(36) The weather/the food/the lava was so/very/extremely/incredibly hot.

In contrast, several phrasal non-heads in our study allow for such resolution due to their verbosity, or the abundance of lexical material. In $(37 a, b)$, for example, we do find hints as to what region on the temperature scale is being referenced, while the non-head in $(37 \mathrm{c})$ is informative as regards what kind of heat hot refers to. In similar fashion, the non-head in $(37 \mathrm{~d})$ contributes to resolving the inherent vagueness of the dimension adjective narrow:

(37) (a) It will be hot at times, late-summer day-at-the-beach sweat-down-your-back hot [weather mapped on TEMPERATURE scale]

(b) They come from the Home Made Bakery in Wailuku which will sell them only straight-out-of-the-oven hot: [...] [food mapped on TEMPERATURE scale]

(c) They're spicy but not rip-your-lips-off hot; aromatic but not perfumy. [food mapped on PUNGENCY scale]

(d) $[\ldots]$ as steep and bumped as Chute but with creatively whimsical gladed patches; Catamount one-skier-at-a-time narrow and enthrallingly turny; [...] [roughly, accessibility of a passage on a ski piste mapped on WIDTH scale]

Summarizing our investigation of the adjectival heads and their non-heads, we can say that the vast majority of adjectival heads are gradable in our data, which is to be expected given the dominant intensifying semantics described above. Mostly, we find relative adjectives in intensifying constructions, and the majority of heads originate from more subjective notional classes. This property of the head is often exploited by the speaker/writer to generate compounds with an expressive meaning, a characteristic the adjectival phrasal compounds share with other types of phrasal compounds. At times, the non-heads contribute to resolving vagueness and polysemy.

\section{Summary and discussion}

Against claims to the contrary, this article has shown that, in English, adjectival phrasal compounds do exist and are possibly more common than often assumed. Semantically, and structurally, they are similar to non-phrasal adjectival compounds as well as to nominal phrasal compounds. At the same time, they differ crucially from their nominal cousins in certain respects, in particular regarding the semantic relation between non-head and head. The better part of these commonalities can be explained by recourse to compound structure in general, while the differences are due to the 
differences between the head categories: adjectival phrasal compounds are different from nominal phrasal compounds because adjectives differ from nouns. Table 3 gives an overview of non-phrasal adjectival compounds and phrasal adjectival compounds, as attested in COCA. The table shows parallel structures for both types of adjectival compounds. Recall that we excluded structures with measure phrases in non-head position, which is why the example in this cell is given in parentheses.

Let us look at the details. First, mutatis mutandis, adjectival phrasal compounds behave like other adjectival compounds. Semantically, we find both argumental and non-argumental ones. The clearly dominant interpretation is similative-intensifying, although the line between mere intensification, mere similitude, or mixed interpretations is often difficult to draw. Thus, the majority of adjectival phrasal compounds behave essentially like noun-adjective compounds, with similitude oftentimes being established in reference to prototypical or hyperbolic events. Measure terms in nonhead position were excluded from the analysis for theoretical and methodological reasons. Including such expressions would further corroborate the likeness of adjectival compounds and adjectival phrasal compounds in general and also make phrasal compounds far more common. Note that the corpus searches were restricted to nonattributive structural positions, and to items with hyphens and without quotation marks: extending queries to other syntactic contexts and to different punctuations would further increase the frequency of pertinent hits (and potentially also affect the distribution of compounds across the different semantic categories). Adjectival phrasal compounds are not very common, but they are an at least moderately productive class of compounds.

Second, adjectival and nominal phrasal compounds show similar morphosyntactic patterns: they are both semantically and formally right-headed and allow for the same diversity of syntactic structures in non-head position. However, leaving aside the obvious differences in the respective head categories, they clearly differ regarding the typical semantic relations between head and non-head. The literature on nominal phrasal compounds agrees that they are determinative or subkind-establishing, viz. 'classifying' in the terminology used in this article. In contrast, the non-head in adjectival phrasal compounds degree-modifies the adjective in head position in the vast majority of cases. This is the same kind of discrepancy we find when comparing non-phrasal adjectival and nominal compounds, which means that the differences between phrasal adjectival compounds and phrasal nominal compounds emerge naturally from the differences between their head categories.

Table 3. Overview of non-phrasal and phrasal adjectival compounds

\begin{tabular}{lll}
\hline \hline & $\mathrm{N}-\mathrm{A}$ & $\mathrm{XP}-\mathrm{A}$ \\
\hline argumental & reader-friendly & chin-and-nose friendly \\
non-argumental & hospital-clean & eat-off-the-floor clean \\
measure & skin-deep & (1.5-cubic-yard deep) \\
\hline \hline
\end{tabular}


It seems safe to say that canonical adjectives are intrinsically different from canonical nouns: they are non-referential and rely on the referential arguments of noun phrases, while it is typically nouns that (can) denote kinds and, by extension, subkinds (see, e.g., Dölling 1992; Krifka 1995). Moreover, many researchers from various theoretical backgrounds agree that nouns tend to encode complex bundles of a multitude of features or properties, while adjectives usually encode a single feature or property (see, e.g., Givón 2001; Hamann 1991; Pustejovsky 1995; Wierzbicka 1988). For this reason, modification of nouns, be it syntactic or by means of word-formation, straightforwardly allows for subclassification via alterations (or spelling out) of certain features. In contrast, changing the single feature of an adjective tends to make void the adjective's entire contribution (see, e.g., Wierzbicka 1988: 471 for an argument in this vein).

In other words, adjectives are usually one-dimensional, while nouns are multidimensional, which renders subclassification for adjectives a less common phenomenon. Yet, given the nature of the majority of adjectives as gradable predicates, they are prone to degree-modification, while nominal gradability is a by far more restricted phenomenon (see Bolinger 1972; Morzycki 2009; Paradis 2008). This is also reflected in modification patterns in word-formation: by virtue of their head category, most adjectival phrasal compounds exhibit an intensifying semantics.

Overall, this article has come up with some perhaps exciting and some perhaps less exciting news about English compounds. Adjectival phrasal compounds do exist, but they are not very different from other compounds.

Authors' address:

Institut für Anglistik und Amerikanistik

English Language and Linguistics

Heinrich-Heine-Universität Düsseldorf

Universitätsstr. 1

40204 Düsseldorf

Germany

christine.guenther@uni-duesseldorf.de

sven.kotowski@uni-duesseldorf.de

ingo.plag@uni-duesseldorf.de

\section{References}

Bache, Carl \& Niels Davidsen-Nielsen. 1997. Mastering English: An advanced grammar for non-native and native speakers. Berlin and New York: De Gruyter Mouton.

Bauer, Laurie. 1997. Evaluative morphology: A search for universals. Studies in Language 21, 533-75.

Bauer, Laurie. 2017. Compounds and compounding (Cambridge Studies in Linguistics 155). Cambridge: Cambridge University Press. 
Bauer, Laurie \& Rodney Huddleston. 2002. Lexical word-formation. In Rodney Huddleston \& Geoffrey K. Pullum (eds.), The Cambridge grammar of the English language, 1621-721. Cambridge: Cambridge University Press.

Bauer, Laurie, Rochelle Lieber \& Ingo Plag. 2013. The Oxford reference guide to English morphology. Oxford: Oxford University Press.

Bierwisch, Manfred. 1989. The semantics of gradation. In Manfred Bierwisch \& Ewald Lang (eds.), Dimensional adjectives: Grammatical structure and conceptual interpretation, 71261. Berlin and Heidelberg: Springer.

Bjarnadóttir, Kristín. 2017. Phrasal compounds in Modern Icelandic with reference to Icelandic word formation in general. In Trips \& Kornfilt (eds.), 11-45.

Bolinger, Dwight. 1972. Degree words. Mouton: The Hague.

Booij, Geert. 2010. Construction morphology. Oxford: Oxford University Press.

Davies, Mark. 2008. The Corpus of Contemporary American English: $400+$ million words, 1990-present. https://corpus.byu.edu/coca/

Davies, Mark. 2013. The Corpus of Contemporary American English (full text on CD): 440 million words, 1990-2012. https://corpus.byu.edu/coca/

Dixon, R. M. (ed.). 1982. Where have all the adjectives gone? Berlin and New York: Mouton.

Dölling, Johannes. 1992. Flexible Interpretation durch Sortenverschiebung. In I. Zimmermann \& A. Strigin (eds.), Fügungspotenzen, 23-62. Berlin: Akademie Verlag.

Emonds, Joseph. 1972. Evidence that indirect object movement is a structure-preserving rule. Foundations of Language 8, 546-61.

Fleischer, Wolfgang \& Irmhild Barz. 1995. Wortbildung der deutschen Gegenwartssprache, 2nd edn. Tübingen: Niemeyer.

Frawley, William. 1992. Linguistic semantics. Hillsdale, NJ: Lawrence Erlbaum.

Givón, Talmy. 2001. Syntax: An introduction, rev. edn. Amsterdam: John Benjamins.

Günther, Christine. 2018. The rich, the poor, the obvious: Arguing for an ellipsis analysis of 'adjectives used as nouns'. In Alex Ho-Cheong Leung \& Wim van der Wurff (eds.), The Noun Phrase in English: Past and present, 77-112. Amsterdam: John Benjamins.

Hamann, Cornelia. 1991. Adjectives. In Arnim von Stechow \& Dieter Wunderlich (eds.), Semantik (Handbücher zur Sprach- und Kommunikationswissenschaft/HSK), 657-74. Berlin: De Gruyter.

Haspelmath, Martin. 1999. Why is grammaticalization irreversible? Linguistics 37(6), 1043-68.

Hein, Katrin. 2011. Phrasenkomposita: Ein wortbildungsfremdes Randphänomen zwischen Morphologie und Syntax? Deutsche Sprache 11(4), 331-61.

Hoeksema, Jack. 2012. Elative compounds in Dutch: Types and historical development. In Guido Oebel (ed.), Crosslinguistic comparison of intensified adjectives and adverbs, 97142. Hamburg: Verlag Dr Kovac.

Jackendoff, R. S. 1973. The base rules for prepositional phrases. In Stephen R. Anderson and Paul Kiparsky (eds.), A Festschrift for Morris Halle, 345-56. New York: Holt, Rinehart \& Winston.

Kennedy, Chris. 2007. Vagueness and grammar: The semantics of relative and absolute gradable adjectives. Linguistics and Philosophy 30(1), 1-45.

Kennedy, Chris. 2013. Two sources of subjectivity: Qualitative assessment and dimensional uncertainty. Inquiry 56(2), 258-77.

Kennedy, Chris \& Louise McNally. 2005. Scale structure, degree modification, and the semantics of gradable predicates. Language 81, 345-81. 
Krifka, Manfred. 1995. Common nouns: A contrastive analysis of Chinese and English. In Gregory N. Carlson \& Francis Jeffry Pelletier (eds.), The generic book, 398-411. Chicago: University of Chicago Press.

Kunter, Gero. 2016. Coquery: A free corpus query tool. www.coquery.org

Lawrenz, Birgit. 2006. Moderne deutsche Wortbildung. Phrasale Wortbildung im Deutschen: Linguistische Untersuchung und sprachdidaktische Behandlung. Hamburg: Verlag Dr Kovac.

Levi, Judith N. 1978. The syntax and semantics of complex nominals. New York: Academic Press.

Lieber, Rochelle. 1988. Phrasal compounds in English and the morphology-syntax interface. Chicago Linguistic Society 24, 398-405.

Lieber, Rochelle \& Pavol Štekauer (eds.). 2009. The Oxford handbook of compounding (Oxford Handbooks in Linguistics). Oxford and New York: Oxford University Press.

Marchand, Hans. 1969. Categories and types of Present-Day English word-formation, 2nd edn. Munich: C. H. Beck.

McNally, Louise \& Gemma Boleda. 2004. Relational adjectives as properties of kinds. In Patricia Cabredo-Hofherr \& Olivier Bonami (eds.), Empirical issues in syntax and semantics, 179-96. Paris: Université Paris 7.

Meibauer, Jörg. 2003. Phrasenkomposita zwischen Wortsyntax und Lexikon. Zeitschrift für Sprachwissenschaft 22(2), 153-88.

Meibauer, Jörg. 2007. How marginal are phrasal compounds? Generalized insertion, expressivity, and I/Q-interaction. Morphology 17, 233-59.

Meibauer, Jörg. 2015. On ' $R$ ' in phrasal compounds: A contextualist approach. In Trips \& Kornfilt (eds.), 241-61.

Morzycki, Marcin. 2009. Degree modification of gradable nouns: Size adjectives and adnominal degree morphemes. Natural Language Semantics 17(2), 175-203.

Morzycki, Marcin. 2012. Adjectival extremeness: Degree modification and contextually restricted scales. Natural Language and Linguistic Theory 30(2), 567-609.

Morzycki, Marcin. 2016. Modification. Cambridge: Cambridge University Press.

OED (2017). The Oxford English Dictionary online. www.oxforddictionaries.com

Paradis, Carita. 2008. Configurations, construals and change: Expressions of DEGREE. English Language and Linguistics 12, 317-43.

Partee, Barbara H. 1995. Lexical semantics and compositionality. In Lila R. Gleitman \& Mark Liberman (eds.), Invitation to cognitive science, 2nd edn, vol. I: Language, 311-59. Cambridge, MA: MIT Press.

Pullum, Geoffrey K. \& Rodney Huddleston. 2002. Prepositions and preposition phrases. In Rodney Huddleston \& Geoffrey K. Pullum (eds.), The Cambridge grammar of the English language, 597-661. Cambridge: Cambridge University Press.

Pustejovsky, James. 1995. The generative lexicon. Cambridge: Cambridge University Press.

Rainer, Franz. 2015. Intensification. In Peter O. Muller, Franz Rainer, Susan Olsen \& Ingeborg Ohnheiser (eds.), Word-formation, 1339-51. Berlin and Boston: De Gruyter.

Rotstein, Carmen \& Yoad Winter. 2004. Total adjectives vs partial adjectives: Scale structure and higher-order modifiers. Natural Language Semantics 12(3), 259-88.

Schneider, Viktoria (2016). Phrasal compounds in English. BA thesis, Heinrich-Heine University, Düsseldorf.

Solt, Stephanie. 2016. Ordering subjectivity and the absolute/relative distinction. In Nadine Bade, Polina Berezovskaya \& Anthea Schöller (eds.), Proceedings of Sinn und Bedeutung 20, 676-93. Tübingen: University of Tübingen. 
ten Hacken, Pius (ed.). 2016. The semantics of compounding. Cambridge: Cambridge University Press.

Trips, Carola. 2012. Empirical and theoretical aspects of phrasal compounds: Against the 'syntax explains it all' attitude. In Angela Ralli, Geert Booij, Sergio Scalise \& Athanasios (eds.), Online proceedings of the eighth Mediterranean Morphology Meeting, 322-46. Patras: University of Patras.

Trips, Carola. 2014. How to account for the expressive nature of phrasal compounds in a conceptual-semantic framework. SKASE Journal of Theoretical Linguistics 11(1), 33-61.

Trips, Carola. 2016. An analysis of phrasal compounds in the model of parallel architecture. In Pius ten Hacken (ed.), The semantics of compounding, 153-77. Cambridge: Cambridge University Press.

Trips, Carola \& Jaklin Kornfilt. 2015a. Phrasal compounds from a typological and theoretical perspective. STUF-Language Typology and Universals 68(3), 281-321.

Trips, Carola \& Jaklin Kornfilt (eds.). 2015b. Typological and theoretical aspects of phrasal compounds, special issue of Language Typology and Universals 68(3).

Trips, Carola \& Jaklin Kornfilt (eds.). 2017. Further investigations into the nature of phrasal compounding. Berlin: Language Science Press.

Wierzbicka, Anna. 1988. The semantics of grammar. Amsterdam: John Benjamins.

Wiese, Richard. 1996. Phrasal compounds and the theory of word syntax. Linguistic Inquiry 27 (1), 183-93.

Zwicky, Arnold M. \& Geoffrey K. Pullum. 1987. Plain morphology and expressive morphology. Annual Meeting of the Berkeley Linguistics Society 13, 330-40. 